\title{
Cutting Brussels sprouts: Collaboration involving persons with dementia
}

\author{
Lars-Christer Hydén
}

\section{Linköping University Post Print}

\section{Tweet}

N.B.: When citing this work, cite the original article.

Original Publication:

Lars-Christer Hydén , Cutting Brussels sprouts: Collaboration involving persons with dementia, 2014, Journal of Aging Studies, (29), 115-123.

http://dx.doi.org/10.1016/j.jaging.2014.02.004

Copyright: Elsevier http://www.elsevier.com/

Postprint available at: Linköping University Electronic Press

http://urn.kb.se/resolve?urn=urn:nbn:se:liu:diva-105443 
CUTTING BRUSSELS SPROUTS: COLLABORATION INVOLVING PERSONS WITH DEMENTIA

ACCEPTED FOR PUBLICATION IN JOURNAL OF AGING STUDIES (2014)

Lars-Christer Hydén, Ph D

Center for Dementia Research (CEDER)

Linköping University

58183 Linköping

Sweden

Lars-Christer.Hyden@liu.se 


\section{Abstract}

How people with dementia collaborate with other people is an area in need of more research and conceptualizations. Collaboration introduces a number of new possibilities and demands concerning cognitive and linguistic abilities and it is suggested that a theoretical framework that emphasize that cognitive resources are not exclusively individual, but are part of cognitive and communicative context. In this article focus is on joint activities and their collaborative organization is analyzed using an example involving persons with dementia working together with staff preparing a meal. The analysis shows that persons with dementia are able to collaborate in fairly advanced activities if they are supported in such a way that they can make use of the cognitive and linguistic resources of others, in particular cognitive functions having to do with planning and execution of actions. The organization of artifacts like kitchen tools can function as an external memory support. The results support a theoretical framework that help to understand what people can do together rather than focus on individual abilities. The results also indicate that is possible to learn how to organize collaboration involving persons with dementia by understanding how other persons abilities as well as artifacts can be used as external resources for support of cognitive and linguistic abilities.

Keywords: Dementia, collaboration, interaction, scaffolding, distributed cognition 


\section{Introduction}

By tradition most of the research on persons with dementia has focused on individuals and their cognitive abilities, their speech, or their actions. Theoretically this research is often based on the idea that cognitive and linguistic abilities belong to the individual and can be found "inside" the skull of the individual - sometimes even being located in specific places in the brain (Morris \& Becker, 2004; Miller \& Boeve, 2009). This kind of research is of course beneficial in many ways as it helps to better understand dementia as a progressive brain disease. At the same time, it is a theoretical framework that limits the understanding of how people with dementia actually cope with and live with dementia in their everyday lives, especially in what ways collaboration with others can facilitate cognitive and linguistic processes and compensate for the consequences of the disease.

Very little research exists on persons with dementia doing things together with others, either with persons without dementia - such as other family members or professional staff - or with other persons with dementia. Most persons with dementia spend a considerable time after getting a diagnosis at home with the family first, and later on in some kind of residential care. In all these settings the person with dementia interacts with other people; they do things together such as conversing, preparing food, or doing recreational activities. They may also be involved in some kind of training or rehabilitation activities aimed at enhancing memory abilities. In these settings the persons with dementia have to use not only their cognitive and linguistic abilities in general, but more specifically they use these abilities in coordination with other people. They need to analyze, plan, and execute actions not only for themselves, but also in coordination with other persons. At the same time it becomes possible for persons with dementia to use other persons' cognitive and linguistic abilities, as those other persons may have better working or episodic memories. In other words, people with dementia do in fact collaborate with other people, which is something that introduces a number of new possibilities and demands concerning cognitive and linguistic abilities. What is needed is thus a theoretical alternative emphasizing that cognitive resources are not exclusively individual, but are part of cognitive and communicative context, an ecosystem (Goodwin, 2004; Hutchins, 2010).

In this article focus will be on joint activities and their collaborative organization. Notions and concepts from socio-cultural research on collaboration will be used (Clark, 1996; Hutchins, 1996; Lave \& Wenger, 1991; Rogoff, 1998). In order to demonstrate and suggest how this 
tradition can be used and what it can yield, an example involving a number of persons with dementia working together with staff preparing a meal is analyzed and discussed. The aim of this article is less to develop a theoretical framework grounded in the data, and more to use and develop a theoretical framework that has been used in other areas (developmental psychology, cognitive psychology) and investigate what theoretical and practical insights might be gained from this in the field of dementia studies.

\section{Dementia and everyday activities: Previous research}

Although many persons with dementia live at home after their diagnosis, the knowledge and research about how they actually perform everyday tasks and chores is very limited. In a review of the literature, Egan and his colleagues (Egan, Hobson \& Fearing, 2006) write that researchers have identified progressive difficulties "with instrumental and personal activities of daily living among persons with dementia, although the speed of decline in function" varies individually (p. 133; see also Nygård, Amberla, Bernspång, Almkvist \& Winblad, 1998; Rusted \& Sheppard, 2002; Wharton \& Monk, 2008). Often neuropsychological theories have been used to explain this decline (see for instance Cooper, Schwartz, Yule \& Shallice, 2005; Giovannetti, Libon, Buxbaum \& Schwartz, 2002; Schwarz, 2006). Common to these theories is the explanation of omissions and problems in the performance of everyday activities as a result of a general cognitive decline in the individual (Schwartz, 2006), or a decline in more specific cognitive functions such as executive control and episodic memory (Giovannetti, Bettcher, Libon, Kessler \& Duey, 2008).

A number of researchers have argued that it is also important to include the role of significant others in the performance of activities and to focus on collaboration between spouses, for instance, as well as with care staff in everyday settings. Some studies have focused on activities at nursing homes, mainly reporting the activities (Adam, Van der Linden, Juillerat \& Salmon, 2000), while others have collected data through extensive observation and interviewing.

In a study of residents in a nursing home for persons with dementia, it was found that while many of the persons preferred to perform the everyday occupations they had pursued previously, some enjoyed just being in “the atmosphere of doing” (Van't Leven \& Jonsson, 2002). The residents also reported that they were dependent on staff in order to perform certain everyday activities, while they did not collaborate with the other residents. Other 
researchers have focused on the collaboration between spouses. In a study of couples with dementia, Vikström and her colleagues (Vikström, Borell, Stigsdotter-Neely \& Josephsson, 2005) found that the healthy spouse generally used two strategies - creating a supportive working climate and using "practical support when performing an everyday occupation together with the spouse" (p. 152). They also noticed that sometimes this support could be either insufficient or inappropriate, resulting in confusion in the persons with dementia. They concluded that "it seemed beneficial for the person with dementia (and indirectly toward the fulfillment of the task) that the caregiver took on the responsibility for performing the activity” (p. 156). In a further analysis of the data Vikström and colleagues (Vikström, Josephsson, Stigsdotter-Neely and Nygård, 2008) investigated how both spouses experienced the changes in the performance of everyday life. It was found that one of the main struggles for the healthy spouses was the lack of initiative and engagement in activities by the spouse with dementia. As a result healthy spouses constantly alternated between taking over the chores and encouraging the spouse with dementia to do the chore according to his/her ability, and collaboration and lowering of demands on the outcome was central.

These studies point to the fact that caregivers often help to plan activities and also to monitor the spouse with dementia in order for the activities to be completed, and for the person with dementia to be able to continue to participate in activities. Other researchers have reported similar findings (Jansson, Nordberg, \& Grafström, 2001; Phinney, 2006; Tsunaka \& Chung, 2012; Hasselkus \& Murray, 2007; Egan et al., 2006).

The center of attention in most of these studies has been on the experience of both the persons with dementia and the caregivers or the staff. There has been less emphasis on the organization of the actual collaboration between persons with dementia and others. Nevertheless it can be argued that at least two conclusions are worth pursuing in this context. First, several studies indicate that persons with dementia are more successful in performing everyday tasks if they collaborate with others as participants in the activities. Second, in order to understand the performance of everyday activities less in terms of individual cognitive abilities but rather as part of a cognitive and communicative ecosystem it is important to rethink the traditional, individualist theoretical framework for understanding cognition and communication as part of everyday collaborative activities (cf. Goodwin, 2004; Hutchins, 2010). 
Collaboration as a cognitive and communicative ecosystem

Even if collaboration is a pervasive human activity most researchers by tradition has focused on the individual's behavior and performance although it is possible to identify a burgeoning interest in collaboration and distributed cognition. A number of philosophers have attempted to conceptualize collaboration (Bratman, 1992; Gilbert, 1990) and distributed cognition (Clark \& Chambers, 1998). Developmental psychologists have suggested that collaboration between children as well as with grown-ups are essential for understanding psychological development (Lave \& Wenger, 1991; Rogoff, 1998). Other researchers have pointed out that many cognitive tasks as well as the performance of many everyday chores presuppose collaboration between several persons and that they share cognitive resources in the collaborative process (Barnier, Sutton, Harris \& Wilson, 2008; Clark, 1996; Hutchins, 1996; Michaelian \& Sutton, 2013; Sawyer, 2003). Finally a number of researchers have shown how persons with cognitive and communicative disabilities can communicate and solve problems through collaboration with others and compensate cognitive loss by drawing on the cognitive and linguistic resources of other participants (Dixon \& Gould, 1998; Goodwin, 2004; Harris, Keil, Sutton, Barnier \& McIlwain, 2011; Müller \& Mok, 2013).

It is suggested here that these theories about collaboration and distributed cognition might serve as an inspiration for understanding how persons with dementia collaborate with others in performing everyday activities. An important implication of this theoretical framework is that participants in a collaboration that involves persons with dementia use the same interactive strategies and share cognitive resources in similar ways to those that can be found in almost all areas of collaboration between persons. What is special when persons with dementia are involved is that the participants must find ways to divide the responsibility for organizing the interaction, making contributions as well as for the distribution of cognitive and linguistic resources. This is true for all collaboration that involves participants with asymmetric access to cognitive and linguistic resources.

Performing everyday activities together with other persons is to engage in joint activities. As has been suggested by Clark (1996), doing things together means that each individual makes contributions to the ongoing activity - something that implies that the contributions of the participants must be coordinated and collaborative (Clark, 1996). It is thus crucial in joint activities that the participants are mutually responsive to each other's actions, treat these as contributions to the joint activity, and are mutually supportive in helping each other to 
complete the joint activity (Clark \& Schaefer, 1987, 1989; Hydén 2011, 2014). Joint activity progresses through the addition of new contributions, thus adding to the common ground. It is important to note that by adding new contributions to the common ground and by negotiating each new contribution, the participants don't need a precise shared plan of the activity. They don't need a shared analysis of how to proceed, or a shared activity goal. Instead, the joint activity progresses through each individual contribution - its negotiation and nesting to previous contributions and to the next contribution. This makes it possible for the participants to constantly and jointly monitor and revise their activity (Clark, 1996). It also makes it possible for them to consider all contingencies that emerge and happen while they are doing something. In those cases the participants actually are doing something in relation to some kind of "goal" (like preparing a meal using a recipe), the nesting of contributions allows them to creatively solve problems that occur during the process and also to actually re-interpret the goal (the recipe) as the activities proceed.

The individual contributions draw on various cognitive and linguistic resources needed to verbally communicate, to remember something, or to suggest a solution to a problem. Researchers interested in human activity "in the wild" (Hutchins, 1996), that is, activity in various open contexts, have suggested that cognitive processes are distributed. In an article Hollan and his colleagues (Hollan, Hutchins \& Kirsh, 2000) suggested that cognitive processes could be distributed across the members of a social group as well as between internal and external material structures, i.e. artifacts (Hollan et al., 2000, p. 176). In other words, cognitive as well as communicative resources are the result of a contextual system consisting of several elements, above all other persons and their abilities, and artifacts. For instance, a person who is trying to tell a story but having problems with remembering something can be helped by someone else who can remember more easily; thus the first person can continue to tell the story. Together - as an organized system - they can tell the story, although the individual could not do so (Goodwin, 2004). Persons can also use artifacts like texts, photos, or computers in performing tasks, as well as doing things like arranging all jars in a cupboard in a certain way, making it easier to find a specific jar (Kirsh, 1995). Thus cognition and communication in joint activities can be seen to consist of several elements (persons and their abilities, artifacts) that can organized in such a way that the new cognitive and communicative system can accomplish things that the individuals could not. 
This theoretical framework describing communication and cognition in joint activities as part of a situated ecosystem can be helpful in describing and understanding joint activities that involve persons with dementia. Persons with dementia progressively lose linguistic and cognitive abilities and thus some of their resources for collaboration with others. One way to deal with this problem is to change the division of contributions between the participants. Those without dementia will, for instance, have to make more contributions to the joint activity, be more responsible for the planning of the activity, be more engaged in advanced repair work and help remember and keep track of what has already been accomplished. In these ways, together with the person with dementia they engage in scaffolding; together they organize the collaboration in such a way that the person with dementia can access those communicative and cognitive resources needed in order to continue participating in collaboration (Hydén, 2011, 2014). Part of this reorganization has to do specifically with the use of distributed communicative and cognitive resources, something that has previously been discussed in conversational interaction involving persons with dementia (Müller \& Mok, 2013) and other acquired brain injuries (Duff, Hengst, Tranel \& Cohen, 2008; Duff, Mutlu, Byom \& Turkstra, 2012). Such a re-organization of the contributions will not only increase the possibilities for successfully completing joint activities, but will also help to sustain the personhood of the participants.

\section{Fieldwork and analysis}

One good example of a joint activity and collaboration is when several persons prepare food together - in this case they also follow a recipe. Joint food preparation is quite complicated, as it involves interpreting and following a recipe, gathering various ingredients, preparing these ingredients, and so on. All steps in the process must be taken in a certain sequence and be ordered temporally. When several persons are involved their actions must be coordinated, not only between the participants but also temporally. All steps must also be related to the recipe and at each step it is possible to check what has been achieved with the recipe and to plan ahead.

The individual contributions to the joint food preparation thus involve the use of many types of cognitive and communicative resources: planning and sequencing motor actions, the ability to remember what has been done and what is planned ahead, and the construction of verbal utterances (directives, questions). The involvement of cognitive and linguistic resources 
implies that persons with dementia who have lost some of these resources face severe problems as participants in this kind of joint activity.

The following extended episode involves persons with dementia working together with members of the staff at a day care center for persons with dementia, and will be analyzed utilizing the theoretical framework suggested above. The fieldwork at the day care center was part of a project aiming at understanding collaboration and identity among persons with earlyto mid-stage dementia. For the day care center data a number of ongoing everyday activities were videotaped. The fieldwork had been going on for some months when the current episode occurred.

The setting is a late morning two weeks after Christmas. Four women - two diagnosed with dementia, and two members of the staff - have decided to prepare a new dish: Brussels sprouts au gratin, based on a recipe that one of the members of staff found in a journal. One of the women diagnosed with dementia (Gunilla) was 62 years old and diagnosed with earlyonset dementia. She had severe problems producing any utterances and most of the time only says "yes" and occasionally some other words; she also had severe memory problems. The other woman with dementia (Eva) was 57 years old, also diagnosed with early-onset dementia. She was quite fluent linguistically but had severe memory problems. The two members of the staff who participated were Anette, who organizes the activity, and Inger, who also participates in other activities going on at the same time. There are also four men present (all of them persons with various kinds of acquired brain injuries) who wander in and out of the kitchen; some of them take part in the food preparation, while others just hang around and engage in small talk with everyone.

The four women were assembled in the kitchen, which consists of a big area with at least three different spatially and functionally separate zones: (1) a large working table and the refrigerator, (2) the stove area with frying pans, and (3) the washing and dishwashing area. There are cupboards on the walls around the kitchen.

The episode lasts for one hour. It starts with the preparation of the activity: various ingredients and tools are gathered and organized on a table and around the stove. Then the preparation of the ingredients starts: the participants chop the onions, the garlic, and the Brussels sprouts while they are seated around the table. Finishing this work, all participants 
move from the table to the stove area and start to cook the ingredients. As ingredients are ready they are arranged in various bowls and gradually the gratin emerges and is put into the oven. Simultaneously a number of other activities are pursued; other persons enter and exit the kitchen, commenting on what is going on, engaging in ongoing conversations, and so on. While the four main participants are chopping the ingredients they engage in side activities like small talk, commenting on Christmas, previous experiences of gratins, etc. Some of the participants are also preparing other dishes at the same time; finally, they also set the table. The fact that many activities and side activities are going on at the same time and that people enter and exit the kitchen means that the individual participants must be able to coordinate their attention and their contributions in relation to both the different activity and participant frames (Hanks, 1990).

Watching the one-hour video, it is not obvious who is a person with dementia and who is not. The interaction is seamless, with very few repairs or other kind of interruptions. In other words, there are few indications of the effects of cognitive and linguistic loss. It is only when two analytical strategies are used that it becomes possible to understand that the collaboration is organized in such a way that the possible challenges facing the persons with dementia do not stand out. The first strategy is to look at the video repeatedly and note the differences in contributions between the participants. It then becomes obvious that, for instance, one of the persons with dementia rarely says anything - and if she does, the only word construction she uses is some variation of "yes". It also becomes evident that the persons with dementia rarely initiate any exchange, something that can result in their just standing without doing anything for extended periods of time. It also becomes clear that one of the staff members is the one who takes all initiatives in terms of starting, overseeing, and ending all the sub-projects that make up the work of making a gratin. She is also the one who at all times supports the two persons with dementia. The second strategy is also to use knowledge about the persons with dementia from other episodes outside the present one. A number of recordings - including one interview - are available that include either both women and or one of them. From this supplemental data it is obvious that these two women are severely challenged both cognitively and linguistically.

In the following, four examples from this episode will be selected, analyzed, and discussed. The first example is chosen because it helps understanding of how the organization of the tools and vegetables on the worktable is used as an external focus of attention and a memory 
aid. The use of external artifacts and their organization is something that is ubiquitous throughout the whole episode. The second example shows how one member of the staff uses reading aloud from the recipe as a way of updating all the participants about what has been accomplished and what the next steps are. Finally, the last two examples have been chosen as they illustrate the organization of the collaboration in such a way that the members of staff are able to scaffold the persons with dementia in order for them to be able to take part in the activity.

The video recording was transcribed verbatim, and non-verbal actions were added to the transcript. (Only the excerpts used in this paper were translated to English.) The analysis of the material is based on conversational analysis (Goodwin, 1981) and analysis of collaboration (Clark, 1996; Hutchins, 1996). As the collaboration is videotaped it is possible to take non-verbal actions into account in the analysis.

\section{Chopping Brussels sprouts: Shared attention}

In doing things together it is imperative that the participants have joint attention (Tomasello, 2008). That is, the participants must have their focus on the ongoing activity and often on some aspect of the activity. This might be the ongoing talk, or an object someone is pointing to. If the participants' attention wanders they will have difficulties in actually performing their ongoing activity. One problem for persons with dementia, in particular Alzheimer's disease, is that their attention span tends to be quite short (Parasuraman, 2004), something that creates a problem in sustained interaction. One way to deal with this is to support the attentional process by organizing the objects in the shared perceptual field. Organizing objects in meaningful patterns means that some of what is important is already organized in front of the participants, thus they do not have to constantly organize their attention by themselves (Goodwin, 1994; Kirsh, 1995).

When the four participants are sitting around the table before them they have a well-organized space. Anette had set up the table in a specific way before they sat down and started to work. There are cutting boards in front of each, except the person to the right (Inger) who shares a cutting board with the next person. Anette has a bag of Brussels sprouts in front of her. She trims the Brussels sprouts and then hands them over to the other women. They cut the sprouts into smaller pieces, and put them in the bowl standing in front of them. When they have cut all the Brussels sprouts the same process starts all over again with onions and garlic. During 
the process all of them constantly have their attention and gaze directed at the table and what goes on there. The well-organized table helps the participants to stay focused on what they are doing, and also to keep track of the sequence of actions: taking a Brussels sprout from Anette, putting it on the cutting board, cutting it, and putting it into the bowl. The artifacts that are used - cutting board, knifes, bowls - are all part of embodied practicies and afford actions of the participants (Hutchins, 1996).

When the cutting begins Anette - supported by Inger - demonstrates the cutting process, both by giving verbal instructions and by performing what she is talking about (Example 1).

Example 1 (10:23-10:46)

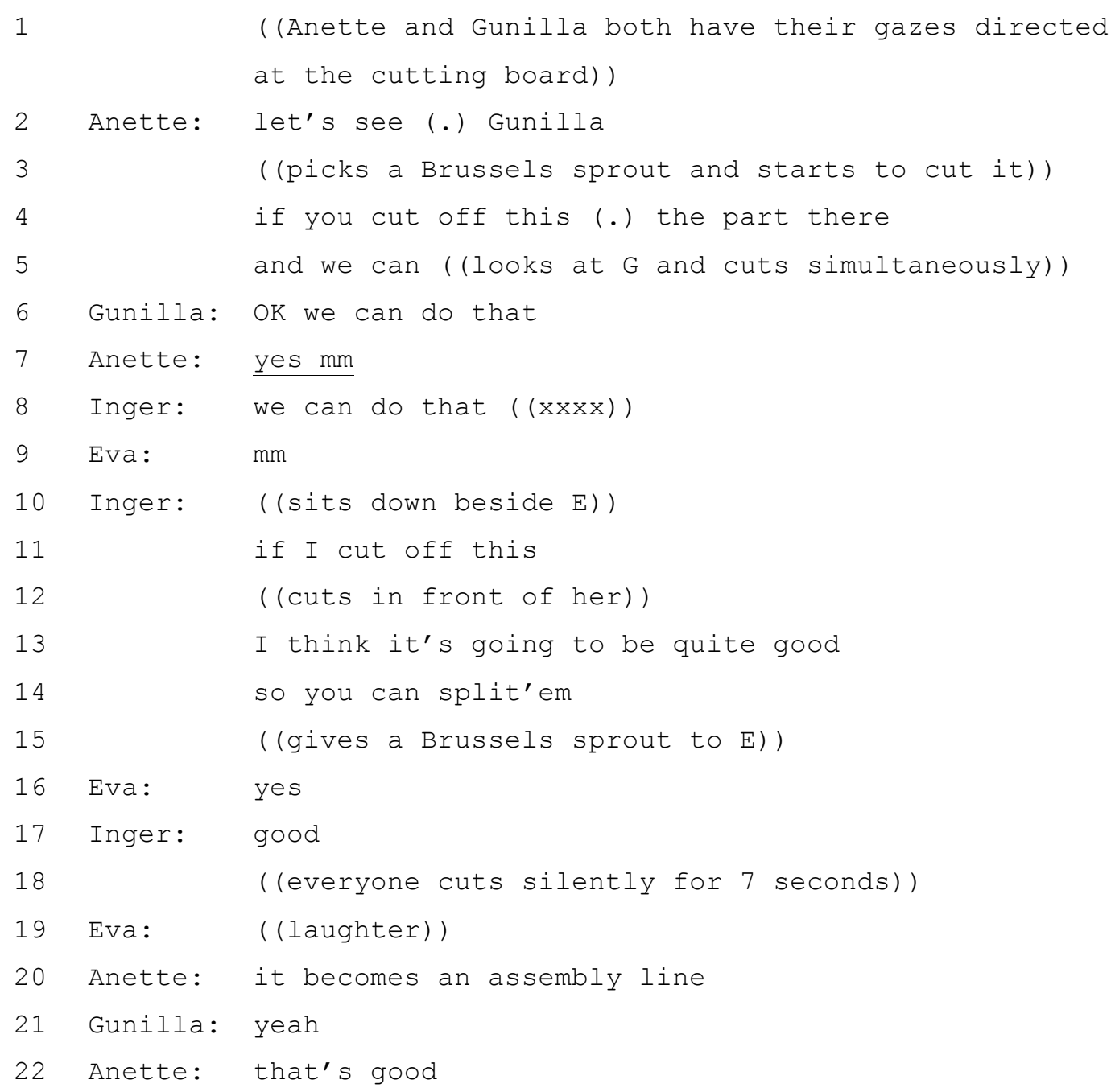

Both Anette and Gunilla have their gazes directed at the cutting boards in front of them, occupied with cutting Brussels sprouts. Anette has been looking at Gunilla's cutting and addresses her by her name in order to get her attention. Anette then picks up a Brussels sprout 
and demonstrates what she wants Gunilla to do by both performing the action and explaining it (Lines 3-7). When Inger sits down besides Eva she engages in the same instructional process with Eva (Lines 10-16). The instructional sequences are organized in the same way: (1) Anette/Inger address Gunilla/Eva in order to get their attention and then (2) perform and verbally explain how to do the cutting, and it ends (3) with a confirmation from Gunilla/Eva. Both Anette and Inger use the pronoun "we" when they address Gunilla and Eva - thus further emphasizing the collaborative character of the activity (cf. Lave \& Wenger, 1991). None of the participants look at each other during the instructional process, but have their attention focused on the knives and the Brussels sprouts.

After the instructional sequences everyone cuts Brussels sprouts for a while and everyone's attention and gaze is directed at the work process on the table. The table and its organization, and the actions by the participants together with the verbal and practical instructions by Anette and Gunilla, function as a collaborative cognitive system, turning all individual actions into a part of an ongoing joint activity. The organization of the artifacts, where people are sitting at the table and what they have in front of them, serve as external groundings and affordances of both attention and the sequential planning of the activity, and thus help to coordinate this quite complex collaborative process. As if to confirm this Eva laughs and Anette comments that they are working like an assembly line (19-22).

\section{Planning and prospective memory}

The making of the Brussels sprouts au gratin is, as already noted, a complex collaborative process. It consists of many small tasks that have to be performed in certain sequences, and then finally added together to make the gratin. All these smaller sub-activities are joined together by a general plan laid down in the recipe. The recipe details the sub-activities and their sequence, but not how the various sub-activities are to be performed - it is up to the participants themselves to make this kind of practical interpretation of the recipe.

During the whole episode above all Anette intermittingly consults the recipe. Especially at the beginning of the work she reads major parts of the recipe aloud so all four participants can hear. She has put the recipe on a small table at the front in the kitchen so that she can easily sneak a look at it as she passes the table. During the preparation of the dish she repeatedly approaches the table with the recipe and reads either silently or aloud (Example 2). 


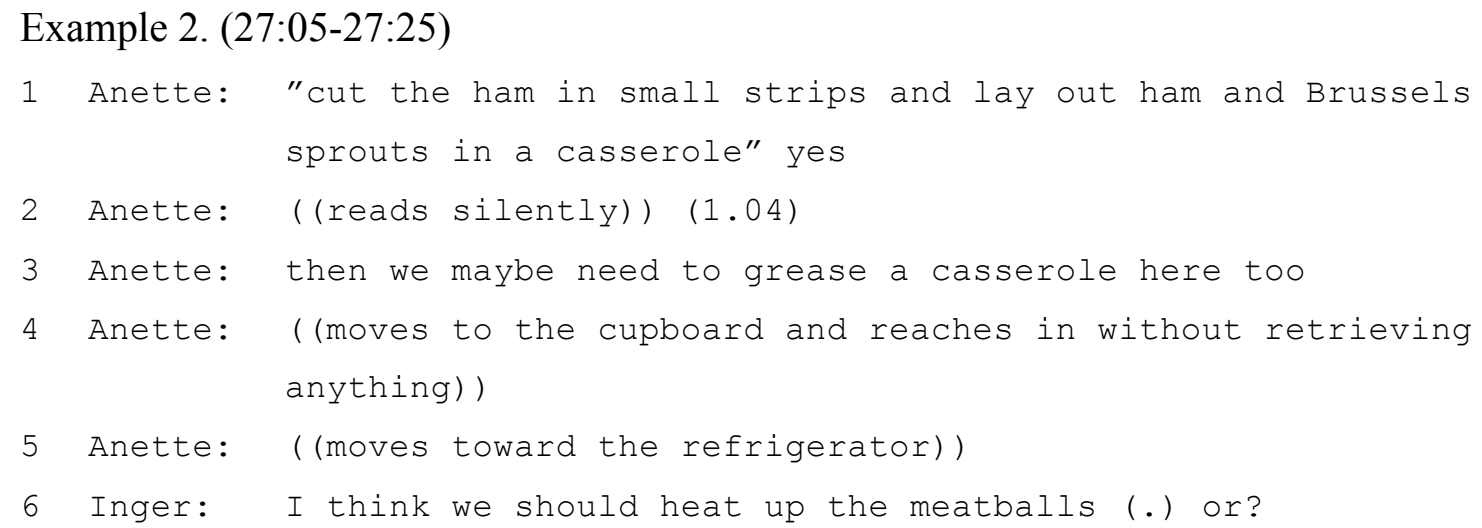

By consulting the recipe and quoting it aloud everyone is able to hear what they are going to do next (Line 1). That is, quoting the recipe serves the function of orienting all the participants to where they are in the process, as well as the function of planning the next step. Thus the recipe also functions as holder of the common ground, reminding everyone of what has been accomplished already. When Anette suggests what they have to do next (Line 3), she makes a practical interpretation of the recipe and suggests a new sub-activity. Her reading aloud from the recipe also functions as an external support for the participants' prospective memory, that is, remembering what they are going to do next. Anette also starts the new subactivity (Lines 4-5). Then Inger adds a new suggestion (Line 6, heating up meatballs), and thus treats the reading of the recipe as a summary of what has been done and what will be done next.

Reading aloud helps to give all sub-activities a part in the general plan and update everyone on how far the gratin-making process has evolved. In doing this, the reading aloud of the recipe takes some of the cognitive load from the individuals (prospective memory, planning) and also supports the coordination of the sub-activities.

\section{Scaffolding}

As already indicated, several activities are going on simultaneously in the kitchen. Some of the male staff members are drifting in and out of kitchen; the females preparing the food often comment on their presence - or rather non-presence and non-participation in the preparation of food. But the women are also preparing several dishes at the same time - although we are only focusing on the Brussels sprouts au gratin. A number of related kitchen activities are also going on, such as checking and organizing the contents of the refrigerator and washing kitchen tools, plates, and cups. 
At one point when Gunilla is sitting at the work table not doing anything in particular, Anette approaches her and asks if Gunilla can help with emptying the dishwasher (Example 3). For Gunilla this is in all likelihood a cognitively quite complex and challenging task. Although it is difficult to see on the video she most probably has problems with the perceptual and cognitive understanding of the organization of the cupboard where all the plates and cups are to be placed. That is, it is probably quite difficult for her to perceptually and categorically discern the organization of the cupboard, as well as planning and organizing the actions needed to empty the dishwasher (picking up a cup and placing it in a specific place).

Example 3. (24:36-24:58)

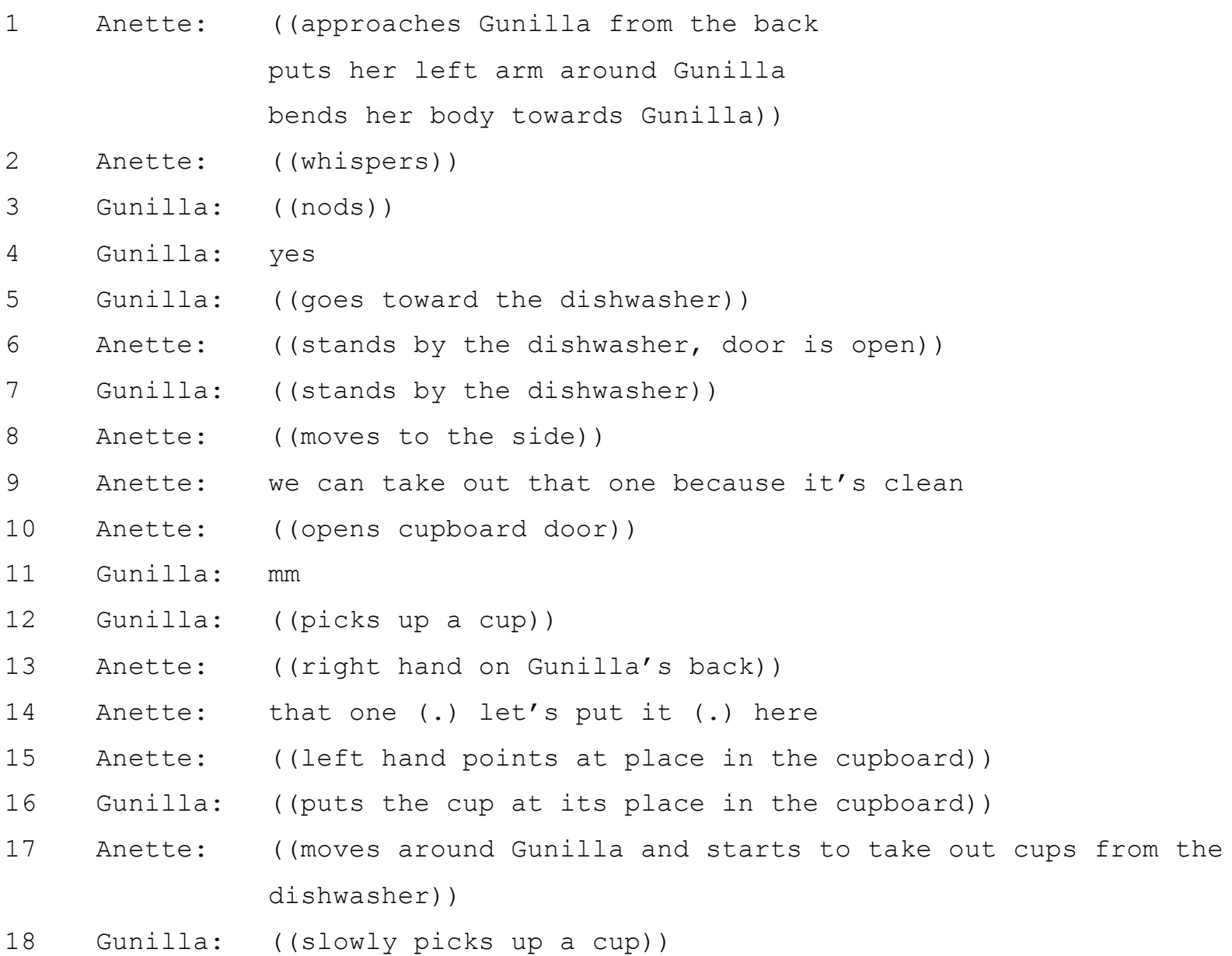

When Anette asks Gunilla to help her with the dishwasher (Line 1-4), Gunilla walks over to the dishwasher where Anette is already standing (Lines 5-7). The clean dishes are already sorted in the dishwasher, thus making it easier to identify what to put where in the cupboard. Anette moves slightly to the side of the dishwasher and takes out a cup (Line 9) and then turns to the cupboard (Line 10). Gunilla also takes out a cup, and Anette then puts her hand on 
Gunilla's back and gently moves her in the direction of the cupboard (Line 13). Anette then gives a verbal instruction, while she at the same time points with her left hand at the space in the cupboard where the cup is supposed to be placed (Line 14-15). Then Gunilla puts the cup in the assigned space (Line 16), thus confirming that she has understood the instruction. Then both of them start to move the cups from the dishwasher into the cupboard (Line 17-18).

Anette is scaffolding Gunilla's action (Hydén, 2011, 2014). That is, she is introducing a task and explains it both practically and verbally. She is also formatting the task in such a way that it becomes possible for Gunilla to perform it. Both in preparing Gunilla as well as during her performance, Anette is actively monitoring Gunilla's action as well as gently supporting her, for instance Anette's hand (Line 13) physically guiding as well as supporting Gunilla.

By organizing the activity in such a way that Anette's own actions and instructions can be seen by Gunilla and used as a template for her own actions, Anette has helped Gunilla to understand the organization of the cupboard and planning and executing the actions needed in order to get the cups (not the plates) to their right place in the cupboard. In other words, Anette presents some of the cognitive resources that Gunilla needs to accomplish the task at hand in such a way that Gunilla can make use of them to organize her own actions successfully. The organization of this sequence is the same as the instruction found in Example 1. The difference is that most of the instructional actions in Example 3 are performed bodily without much use of words.

A similar interactional structure is found in Example 4, although the organization of the collaboration is a bit more complicated. Anette, Gunilla, and Eva are standing in front of the stove performing two different sub-activities at the same time: frying the meat and making a sauce. The noise level is very high around the stove as other conversational interactions are going on in the immediate vicinity. This makes it quite a complicated situation, one that is especially challenging for the two women with dementia, but also for Anette, who is monitoring and scaffolding the two sub-activities.

Example 4. (39:10-40:48)

$\begin{array}{lll}1 & \text { Anette: } & \text { OK let's see } \\ 2 & \text { Eva: } & \mathrm{mm} \\ 3 & \text { Anette: } & \text { can we }\end{array}$




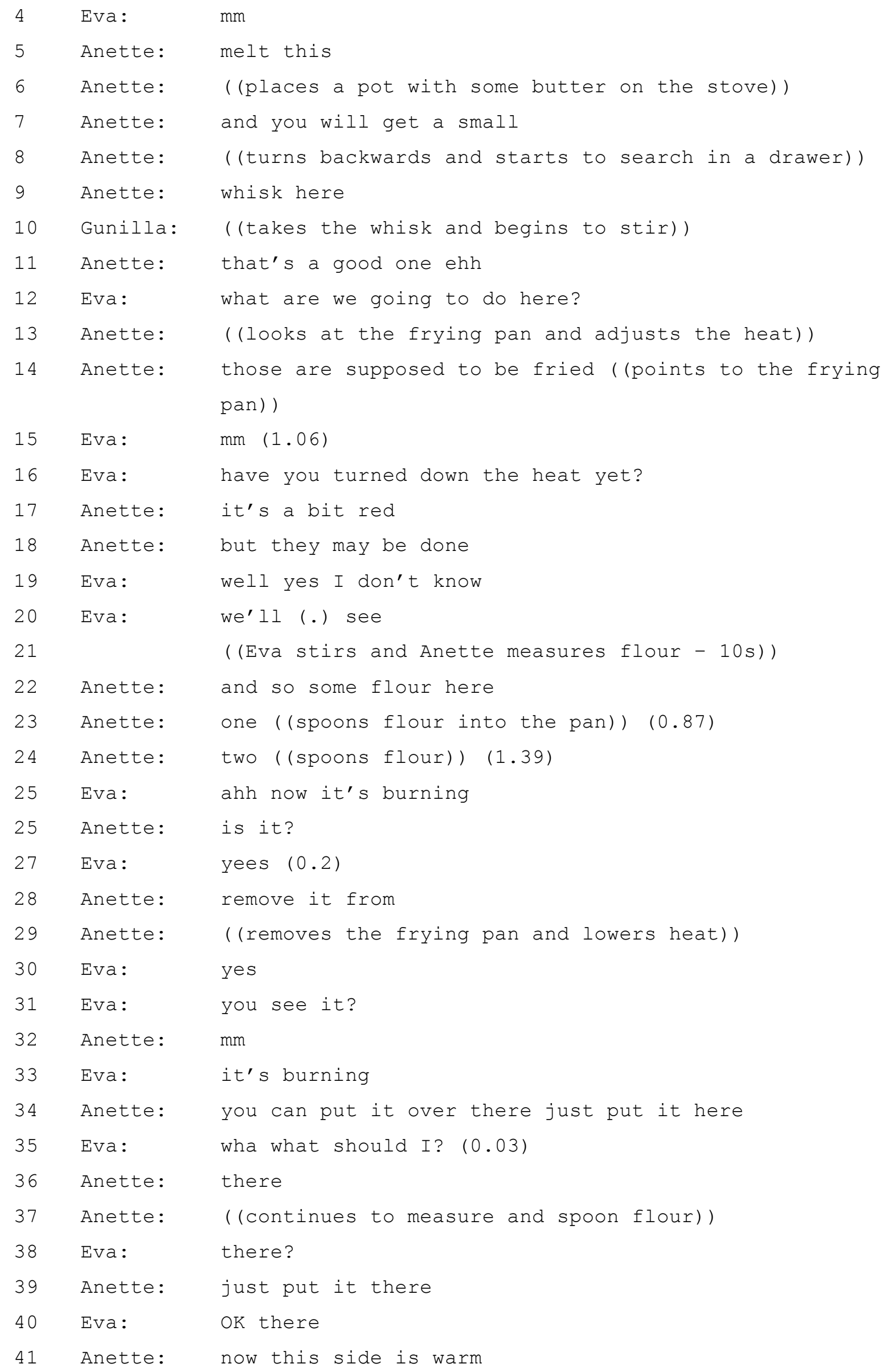




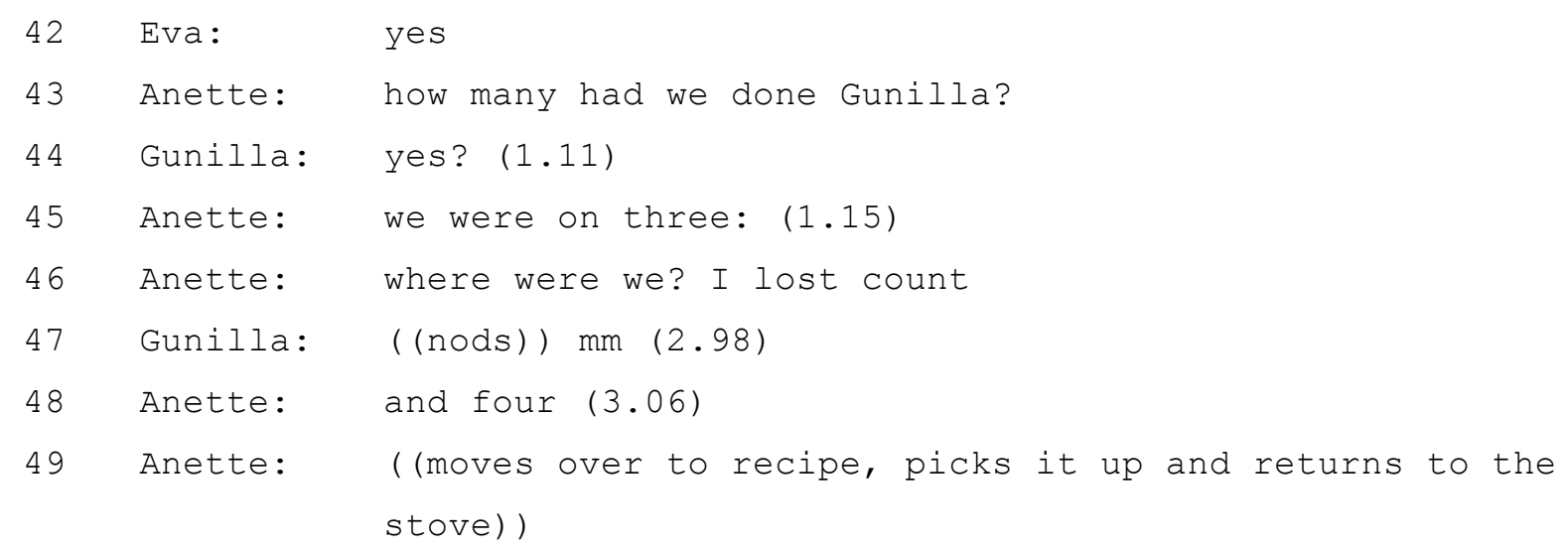

This example is structured around the performance and coordination of two different subactivities, and Anette is moving between them. On Lines 1-11 Anette takes the lead in starting to make the sauce. She is speaking aloud, making it possible for Gunilla to follow the proceedings (Lines 5-9). At the same time she instructs Gunilla to stir the sauce with the whisk (Line 9), which Gunilla confirms by starting to stir (Line 10). At this point Eva catches Anette's attention by asking her what to do (Line 12). She uses the pronoun "we", thus positioning herself as a part of the team rather than being individually responsible for the frying. Anette and Eva negotiate how to fry the meatballs and Eva continues to fry (Line 2021). Anette then shifts her attention to the sauce-making by starting to measure flour (Line 2124). This sub-activity is suddenly interrupted by Eva who points out that the meat is burning (Line 25), which again turns Anette's attention to the frying (Lines 26-36). When Anette again tries to measure flour she is interrupted by Eva (Lines 38-42) before she can return to the measuring and continue to the sauce-making (Line 43-48). She finishes this sub-activity by going over to the recipe in order to start a new sub-activity (Line 49).

As in previous examples, Anette is scaffolding the two sub-activities by monitoring and supporting ongoing actions, and by planning for upcoming actions. She does it by both using verbal instructions, talking aloud to describe what she is doing, and by showing what to do. Again she is introducing templates for stirring and frying that Eva and Gunilla can use on their own in order to continue their sub-activities. She also monitors the two sub-activities and responds to calls for attention; this is what happens both when Anette is regulating the heat (Line 13) and when she helps Eva with the burning meat and with where to put the frying pan (Lines 34, 39-41). In both these cases Anette also provides help with correcting or repairing actions (the heat; taking the frying pan off the stove), and finishing sub-activities (frying, the making of the roux). Thus Anette is providing various kinds of cognitive support: attentional 
support as well as support for executive functions by planning for the next actions, monitoring actions and repairing actions when needed, as well as planning the next new task.

\section{Discussion and conclusions}

The four women preparing the Brussels sprouts au gratin is not an example of what goes on in general at day care centers for people with dementia. Nonetheless, they provide a good and interesting example of what could go on at best. The episode analyzed here is a positive example that shows what is possible and that people with dementia - even at a fairly advanced stage - can take part in joint activities with other persons. It can be seen as a positive example for several reasons. Both women with dementia were not only present during the whole process, but they were also active participants. Although a number of repairs, especially of actions, could be identified, few, if any, face-threatening situations could be found. No withdrawals from interaction by either the staff or the women with dementia could be found. Nor could any communicative breakdowns be identified during the episode. The findings also confirm findings from other researchers, in particular the need for a supportive work climate as well as the need for practical support (Egan et al., 2006; Jansson et al., 2001; Phinney, 2006; Vikström et al., 2005).

The analysis of the episode indicates what can be gained by using a theoretical framework with less focus on the individual's abilities and losses, but rather on trying to understand the individual's actions as part of a communicative and cognitive ecosystem. This theoretical change shifts the perspective from the person with dementia as a solitary agent doing things on his or her own, to that of the person with dementia as a participant in a joint activity. The concept of a participant collaborating with others implies that tasks can be especially designed to fit the person with dementia, but also that the person with dementia can use other persons and artifacts and their organization as resources in making contributions to the joint activity. Thus cognitive functions like executive control, attention, and working memory, as well as episodic memory, can be seen as distributed functions implying that they at least partially are properties of the ecosystem (Dahlbäck, Kristiansson \& Stjernberg, 2013; Hutchins, 2010; Michaelian \& Sutton, 2013). As a consequence the boundaries between individuals in collaborative activities become porous, and the individuals become instead parts in a complex activity. 
Second, in this system a number of redefinitions and redistributions of tasks and resources can be made. The move from the individual with dementia as a problem-solver to the joint activity as a system also points to the importance of describing and understanding how the organization of the collaboration changes in order for the persons with dementia to be able to continue to participate, for instance in terms of scaffolding (Hydén, 2011, 2014).

This approach to joint activities involving persons with dementia has some important practical and clinical implications. The analysis of the episode above indicates that if it is possible to involve persons with dementia in collaboration, then it is also possible to learn how to do it. A number of things stand out as especially important. First, that a positive and supportive work climate is necessary in order to facilitate collaboration. Second, if all participants do not do the same things, it is important to make use of those resources that each person actually is good at. Third, tasks can be subdivided into sets of sub-tasks where some may be more basic while others are of a more general character. Tasks can, for instance, be devised in such a way that there is a fit between task and available resources. Thus (i) a person with access to fewer cognitive and linguistic resources can get simpler tasks; (ii) tasks can be divided into smaller and simpler tasks so that they fit the person's resources; (iii) tasks can be formatted in such a way that they fit the person's available resources; (iv) certain tasks may not be given to certain persons but to others; and (v) cognitive and linguistic resources can be lent to a person in order for that person to accomplish a task. As a result a person can be part of joint activities even if that person has less resources. Finally, the analysis also clearly shows the importance of using instructional sequences involving both practical and oral instructions, as well as monitoring of the performance, suggestions of repairs, feedback, and emotional support.

\section{Acknowledgement}

This study was funded by the by the bank of Sweden Tercentenary Foundation as part of the program Dementia: Agency, personhood and everyday life. Grant no. M10-0187:1.

\section{$\underline{\text { References }}$}

Adam, S., Van der Linden, M., Juillerat, A-C. \& Salmon, E. (2000). The cognitive management of daily life activities in patients with mild to moderate Alzheimer's disease in a day care centre: A case report. Neuropsychological Rehabilitation, 10, 485 509 . 
Barnier, A. J., Sutton, J., Harris, C. B., \& Wilson, B. A. (2008). A conceptual and empirical framework for the social distribution of cognition: The case of memory. Cognitive Systems Research, 9, 33-51.

Bratman, M. E. (1992). Shared Cooperative Activity. The Philosophical Review, 101, 327341.

Clark, A., \& Chalmers, D. (1998). The extended mind. Analysis, 58, 7-19.

Clark, H. H. (1996). Using language. New York: Cambridge University Press.

Clark, H. H., \& Schaefer, E. F. (1987). Collaborating on contributions to conversations. Language and Cognitive Processes, 2, 19-41.

Clark, H. H., \& Schaefer, E. F. (1989). Contributing to discourse. Cognitive Science, 13, 259294.

Cooper, R.P., Schwartz, M., Yule, P., \& Shallice, T. (2005). The simulation of action disorganization in complex activities of daily living. Cognitive Neuropsychology, 22, 959-1004.

Dahlbäck, N., Kristiansson, M., \& Stjernberg, F. (2013). Distributed remembering through active structuring of activities and environments. Review of Philosophy and Psychology, $4,153-165$.

Dixon, R.A., \& Gould, O.N. (1998). Younger and Older Adults Collaborating on Retelling Everyday Stories. Applied Developmental Science, 2, 160-171.

Duff, M. C., Hengst, J. A., Tranel, D., \& Cohen, N. J. (2008). Collaborative discourse facilitates efficient communication and new learning in amnesia. Brain and Language, $106,41-54$.

Duff, M. C., Mutlu, B., Byom, L., \& Tukstra, L.S. (2012). Beyond utterances: Distributed cognition as a framework for studying discourse in adults with acquired brain injury. Seminars in Speech and Language, 33, 44-54.

Egan, M., Hobson, S., \& Fearing, V. G. (2006). Dementia and occupation: A review of the literature. Canadian Journal of Occupational Therapy, 73, 132-140.

Gilbert, M. (1990). Walking Together: A Paradigmatic Social Phenomenon. Midwest Studies in Philosophy, xv, 1-14.

Giovannetti, T., Libon, D.J., Buxbaum, L.J., \& Schwartz, M.F. (2002). Naturalistic action impairments in dementia. Neuropsychologia, 40, 1220-1232.

Giovannetti, T., Bettcher, B. M., Libon, D.J., Kessler, R.K., \& Duey, K. (2008). Coffee with jelly or unbuttered toast: Commissions and omissions are dissociable aspects of everyday action impairment in Alzheimer's Disease. Neuropsychologia, 22, 235-245. 
Goodwin, C. (1981). Conversational organization: Interaction between speakers and hearers. New York: Academic Press.

Goodwin, C. (1994). Professional vision. American Anthropologist, 96, 606-633.

Goodwin, C. (2004). A competent speaker who can't speak: The social life of aphasia. Journal of Linguistic Anthropology, 14, 151-170.

Hanks, W.F. (1990). Referential practice. Language and lived space among the Maya. Chicago: The University of Chicago Press.

Harris, C. B., Keil, P.G., Sutton, J., Barnier, A.J., \& McIlwain, D. J. F. (2011). We Remember, We Forget: Collaborative Remembering in Older Couples. Discourse Processes, 48, 267-303.

Hasselkus, B.R. and Murray, B.J. (2007). Everyday occupation, well-being, and identity: The experience of caregivers in families with dementia. The American Journal of Occupational Therapy, 61, 9-20.

Hollan, J., Hutchins, E., \& Kirsh, D. (2000). Distributed cognition: Toward a new foundation for human-computer interaction research. ACM Transactions on Computer-Human Interaction, 7, 174-196.

Hutchins, E. (1996). Cognition in the wild. Cambridge: MIT Press.

Hutchins, E. (2010). Cognitive ecology. Topics in Cognitive Science, 2, 705-715.

Hydén, L. C. (2011). Narrative collaboration and scaffolding in dementia. Journal of Aging Studies, 25, 339-347.

Hydén, L. C. (2014). How to do things with others: Joint activities involving persons with Alzheimer's Disease. In L. C. Hydén, H. Lindemann \& J. Brockmeier (Eds.), Beyond loss. Dementia, identity, and personhood. (137-154). New York: Oxford University Press.

Jansson, W., Nordberg, G., \& Grafström, M. (2001). Patterns of elderly spousal caregiving in dementia care: An observational study. Journal of Advanced Nursing, 34, 804-812.

Kirsh, D. (1995). The intelligent use of space. Artificial Intelligence, 73, 31-68.

Lave, J., \& Wenger, E. (1991). Situated learning. Legitimate peripheral participation. New York: Cambridge University Press.

Michaelian, K., \& Sutton, J. (2013). Distributed cognition and memory research: History and current directions. Review of Philosophy and Psychology, 4, 1-24.

Miller, B. L., \& Boeve, B. F. (Eds.). (2009). The behavioral neurology of dementia. New York: Cambridge University Press. 
Morris, R., \& Becker, J. (Eds.). (2004). Cognitive neuropsychology of Alzheimer's Disease (2nd ed.). Oxford: Oxford University Press.

Müller, N., \& Mok, Z. (2013). “Getting to know you”: Situated and distributed cognitive effort in dementia. In N. Müller \& Z. Mok (Eds.), Dialogue and dementia: Cognitive and communicative resources for engagement (pp. 61-86). New York: Psychology Press.

Nygård, L., Amberla, K., Bernspång, B., Almkvist, O., \& Winblad, B. (1998). The relationship between cognition and daily activities in cases of mild Alzheimer's Disease. Scandinavian Journal of Occupational Therapy, 5, 160-166.

Parasuraman, R. (2004). Attentional functioning in Alzheimer's disease. In R. Morris \& J. Becker (Eds.), Cognitive neuropsychology of Alzheimer's disease (2nd ed.), (pp. 81102). New York: Oxford University Press.

Phinney, A. (2006). Family strategies for supporting involvement in meaningful activity by persons with dementia. Journal of Family Nursing, 12, 80-101.

Rogoff, B. (1998). Cognition as a collaborative process. In D. Kuhn \& R. S. Siegler (Eds.), Handbook of child psychology, Vol. 2: Cognition, perception, and language (pp. 679744). New York: Wiley.

Rusted, J. \& Sheppard, L. (2002). Action-based memory in Alzheimer's Disease: A longitudinal look at tea making. Neurocase, 8, 111-126.

Sawyer, R.K. (2003). Group Creativity. Music, Theater, Collaboration. Mahwah, N.J.: Lawrence Erlbaum Ass.

Schwartz, M. (2006). The cognitive neuropsychology of everyday action and planning. Cognitive Neuropsychology, 23, 202-221.

Tomasello, M. (2008). Origins of human communication. Cambridge: MIT Press.

Tsunaka, M. \& Chung, J. C. C. (2012). Care-givers' perspectives of occupational engagement of persons with dementia. Ageing \& Society, 32, 543-560.

Van't Leven, N., \& Jonsson, H. (2002). Doing and being in the atmosphere of the doing: Environmental influences on occupational performances in a nursing home. Scandinavian Journal of Occupational Therapy, 9, 148-155.

Vikström, S., Borell, L., Stigsdotter-Neely, A., \& Josephsson, S. (2005). Caregivers’ selfinitiated support towards their partners with dementia when performing an everyday occupation together at home. OTJR: Occupation, Participation and Health, 25, 149159. 
Vikström, S., Josephsson, S., Stigsdotter-Neely, A., \& Nygard, L. (2008). Engagement in activities: Experiences of persons with dementia and their caregiving spouses. Dementia, 7, 251-270.

Wharton, J. P., \& Monk, A. F. (2008). Technological opportunities for supporting people with dementia who are living at home. International Journal of Human-Computer Studies, $66,571-568$. 